\title{
Adrenaline Improves Platelet Reactivity in Ticagrelor-Treated Healthy Volunteers
}

\author{
Sukhi Singh ${ }^{1}$ Tor Damén ${ }^{2,3}$ Andreas Nygren ${ }^{2,3}$ Caroline Shams Hakimi ${ }^{1}$ Sofia Ramström ${ }^{4,5}$ \\ Mikael Dellborg ${ }^{1}$ Tomas L. Lindahl ${ }^{5}$ Camilla Hesse ${ }^{6,7}$ Anders Jeppsson ${ }^{1,8}$
}

${ }^{1}$ Department of Molecular and Clinical Medicine, Institute of Medicine, Sahlgrenska Academy, University of Gothenburg, Gothenburg, Sweden

2 Department of Anaesthesiology and Intensive Care Medicine, Institute of Clinical Sciences, Sahlgrenska Academy, University of Gothenburg, Gothenburg, Sweden

3 Department of Cardiothoracic Anaesthesia and Intensive Care, Sahlgrenska University Hospital, Gothenburg, Sweden

${ }^{4}$ Cardiovascular Research Centre, School of Medical Sciences, Örebro University, Örebro, Sweden

${ }^{5}$ Department of Clinical Chemistry and Department of Clinical and Experimental Medicine, Linköping University, Linköping, Sweden

${ }^{6}$ Department of Clinical Chemistry and Transfusion Medicine, Institute of Biomedicine, Sahlgrenska Academy, University of Gothenburg, Gothenburg, Sweden

${ }^{7}$ Regional Blood Bank, Sahlgrenska University Hospital, Gothenburg, Sweden

8 Department of Cardiothoracic Surgery, Sahlgrenska University

Hospital, Gothenburg, Sweden

Thromb Haemost 2019;119:735-743.

\begin{abstract}
Address for correspondence Anders Jeppsson, MD, PhD, Department of Cardiothoracic Surgery, Sahlgrenska University Hospital, SE-41345 Gothenburg, Sweden (e-mail: anders.jeppsson@vgregion.se).
\end{abstract}

\begin{abstract}
Keywords

- adrenaline

- ticagrelor

- platelet function

- flow cytometry

- impedance aggregometry
\end{abstract}

Background Administration of agents that enhance platelet reactivity may reduce the perioperative bleeding risk in patients treated with the adenosine diphosphate (ADP)-receptor antagonist ticagrelor. Adrenaline potentiates ADP-induced aggregation and activation in blood samples from ticagrelor-treated patients, but it has not previously been evaluated in vivo.

Methods Ten healthy male subjects were included in an interventional study. A loading dose of ticagrelor $(180 \mathrm{mg}$ ) was administered, followed 2 hours later by a gradually increased intravenous adrenaline infusion $(0.01,0.05,0.10$ and $0.15 \mu \mathrm{g} / \mathrm{kg} / \mathrm{min} ; 15$ minutes at each step). Blood pressure, heart rate, platelet aggregation (impedance aggregometry), platelet activation (flow cytometry), clot formation (rotational thromboelastometry) and adrenaline plasma concentration were determined before and after ticagrelor administration and at the end of each adrenaline step.

Results Infusion of adrenaline increased ADP-induced aggregation at all doses above $0.01 \mathrm{\mu g} / \mathrm{kg} / \mathrm{min}$. The aggregation increased from median 17 (25-75th percentiles: $14-31)$ to $25(21-34)$ aggregation units $(p=0.012)$ at $0.10 \mu \mathrm{g} / \mathrm{kg} / \mathrm{min}$. Adrenaline infusion also increased ADP-induced fibrinogen receptor activation (from 29 [22-35] to $46[38-57 \%]$ ) and P-selectin expression (from 3.7 [3.0-4.3] to 7.7 [4.7-8.6\%]), both $p=0.012$. Adrenaline infusion reduced clot formation time (97 [89-110] to 83 received

December 8, 2018

accepted after revision January 3, 2019 (c) 2019 Georg Thieme Verlag KG Stuttgart · New York
DOI https://doi.org/ $10.1055 / \mathrm{s}-0039-1683461$. ISSN 0340-6245. 
[76-90] seconds, $p=0.008$ ) and increased maximum clot firmness (59 [57-60] to 62 [61-64] mm, $p=0.007)$.

Conclusion Infusion of adrenaline at clinically relevant doses improves in vivo platelet reactivity and clot formation in ticagrelor-treated subjects. Adrenaline could thus potentially be used to prevent perioperative bleeding complications in ticagrelortreated patients. Studies in patients are necessary to determine the clinical importance of our observations.

Trial Registry Number ClinicalTrials.gov NCT03441412.

\section{Introduction}

Dual antiplatelet therapy (DAPT) with acetylsalicylic acid and the reversible adenosine diphosphate (ADP) receptor $\left(\mathrm{P} \mathrm{Y}_{12}\right)$ antagonist ticagrelor reduces the risk of thrombotic events compared with acetylsalicylic acid and clopidogrel in acute coronary syndrome patients. ${ }^{1}$ However, DAPT with ticagrelor is also associated with an increased risk of excessive perioperative bleeding if acute surgery becomes necessary. $^{2}$

There is no antidote available for ticagrelor and platelet transfusion has no or very limited effect on ADP-dependent platelet aggregation. $^{3-5}$ It is therefore recommended that ticagrelor should be discontinued 3 days before surgery, ${ }^{6}$ but this cannot always be achieved due to the condition of the patient. Hence, new alternatives to reduce the perioperative bleeding risk in patients on ticagrelor are warranted.

The perioperative bleeding risk in cardiac surgery patients with on-going or recently discontinued DAPT correlates to the residual ADP-dependent platelet aggregability. ${ }^{7-9}$ Even small differences in preoperative platelet aggregability have significant impact on the bleeding risk. ${ }^{7,8}$ Perioperative administration of agents that increase ADP-dependent aggregability might thus be one way to reduce bleeding complications. Adrenaline is a potential agent since platelets express $\alpha_{2 \mathrm{~A}}$-receptors ${ }^{10-13}$ which have the same downstream effects as the $\mathrm{P}_{2} \mathrm{Y}_{12}$-receptor. ${ }^{14-16}$ We have previously shown that adrenaline supplementation concentration-dependently enhances ADP-induced platelet activation and aggregation in blood samples from patients on DAPT with acetylsalicylic acid and ticagrelor. ${ }^{17}$ With adrenaline supplementation in vitro, platelet aggregation reached levels above a previously suggested cut-off of 22 aggregation units for when coronary artery bypass grafting can be performed without an increased bleeding risk. ${ }^{7,8,17}$

In the present study, we hypothesized that adrenaline also improves platelet activation and aggregation, and clot formation in vivo. To test this hypothesis, a study with clinically relevant infusion rates of adrenaline, administered to ticagrelor-treated healthy volunteers, was designed. Furthermore, we wanted to investigate if there is any indirect negative effect of a $\beta$-blocker on platelet reactivity during adrenaline infusion, as $\beta$-blockers may be used to counteract adrenaline's effects on heart rate and blood pressure.

\section{Methods}

\section{Ethical Considerations}

The study was approved by the Regional Research Ethics Committee (no. 669-17, approved September 19, 2017) and the Swedish Medical Products Agency (EudraCT 2017-003111-18) and registered at ClinicalTrials.gov (NCT03441412). The study was performed according to the Declaration of Helsinki and Good Clinical Practice (GCP) guidelines. All study participants gave informed written consent.

\section{Study Participants}

Ten healthy men with a median age of 24 (range: 18-37) years were included in an interventional study during February and March 2018. Exclusion criteria were age $>40$ years, any chronic physical or mental disease or disorder, previous intracranial bleeding, electrocardiography (ECG) abnormalities, chronic medication of any kind and any occasional intake of non-steroidal anti-inflammatory drugs (NSAIDs), aspirin or any other substances that potentially interact with ticagrelor, adrenaline or metoprolol less than 1 week before the investigational visit. Further exclusion criteria were known intolerance or contraindication to ticagrelor, adrenaline or metoprolol, known drug abuse of any kind or unwillingness to refrain from caffeine intake or nicotine use within 24 hours before the start of the treatment. Characteristics of the study participants are given in - Table 1.

\section{Outcome Variables}

The main objective was to assess ADP-induced platelet aggregation at different infusion rates of adrenaline. In addition, platelet aggregation in response to arachidonic acid (AA) and thrombin-receptor activating peptide-6 (TRAP), unstimulated and ADP- and TRAP-induced platelet activation (P-selectin expression and PAC-1 binding), clot formation parameters, adrenaline plasma concentration, blood pressure, heart rate and dyspnoea were assessed.

\section{Study Design}

The study was performed at the Clinical Trials Centre at Sahlgrenska University Hospital. Once informed consent was obtained during the screening visit, information about medical history and medication was collected, followed by a physical examination including heart and lung auscultation, height, weight, blood pressure and heart rate registrations 
Table 1 Baseline characteristics and demographics. Characteristics of the study participants. Values in the left column are the laboratory's normal ranges for adult males and values in the right column are results presented as median (25-75th percentiles). Laboratory values are from the screening visit

\begin{tabular}{|l|l|}
\hline$N$ & 10 \\
\hline Age $(\mathrm{y})$ & $\begin{array}{l}24(19-30), \\
\text { range: } 18-37\end{array}$ \\
\hline Height $(\mathrm{m})$ & $1.82(1.76-1.93)$ \\
\hline Weight $(\mathrm{kg})$ & $83(74-103)$ \\
\hline BMI $\left(\mathrm{kg} / \mathrm{m}^{2}\right)$ & $24(23-30)$ \\
\hline $\begin{array}{l}\text { Platelet concentration } \\
\left(145-348 \times 10^{9} / \mathrm{L}\right)\end{array}$ & $235(222-249)$ \\
\hline Haemoglobin $(134-170 \mathrm{~g} / \mathrm{L})$ & $145(141-151)$ \\
\hline Serum sodium $(137-145 \mathrm{mmol} / \mathrm{L})$ & $142(140-143)$ \\
\hline Serum potassium $(3.6-4.6 \mathrm{mmol} / \mathrm{L})$ & $4.3(4.1-4.5)$ \\
\hline Serum calcium $(2.15-2.50 \mathrm{mmol} / \mathrm{L})$ & $2.37(2.33-2.42)$ \\
\hline Serum creatinine $(60-105 \mu \mathrm{mol} / \mathrm{L})$ & $87(83-101)$ \\
\hline Serum protein $(64-79 \mathrm{~g} / \mathrm{L})$ & $72(66-75)$ \\
\hline Serum ASAT $(0.25-0.75 \mu \mathrm{kat} / \mathrm{L})$ & $0.47(0.34-0.55)$ \\
\hline Serum ALAT $(0.15-1.10 \mu \mathrm{kat} / \mathrm{L})$ & $0.43(0.35-0.54)$ \\
\hline Serum ALP $(0.7-1.9 \mu \mathrm{kat} / \mathrm{L})$ & $1.4(1.1-1.5)$ \\
\hline Serum bilirubin $(5-25 \mu \mathrm{mol} / \mathrm{L})$ & $7.2(6.3-14.0)$ \\
\hline
\end{tabular}

Abbreviations: ALAT, alanine aminotransferase; ALP, alkaline phosphatase; ASAT, aspartate aminotransferase; BMI, body mass index.

and ECG. Screening laboratory tests included haemoglobin and platelet concentration, electrolytes, liver function tests and a urine drug test. If the results showed that the participant was still eligible for participation, the investigational visit was scheduled within 21 days.

On the morning of the investigational visit, a new physical examination as well as a urine drug test was performed before the investigation started. An arterial catheter (BD Arterial Cannula; BD Infusion Therapy Systems Inc., Utah, United States) was inserted in the radial artery for continuous invasive blood pressure and heart rate registration as well as for blood sampling. In addition, a catheter (BD Venflon Pro Safety; BD Infusion Therapy $A B$, Helsingborg, Sweden) was inserted in the brachial vein for drug administration. After the study participant had rested for at least 10 minutes, baseline registrations were conducted including blood pressure and heart rate, dyspnoea assessment (Borg scale $)^{18}$ and blood sampling. An oral loading dose $(2 \times 90 \mathrm{mg}$ ) of ticagrelor (Brilique; AstraZeneca, Mölndal, Sweden) was then administered ( - Fig. 1). Two

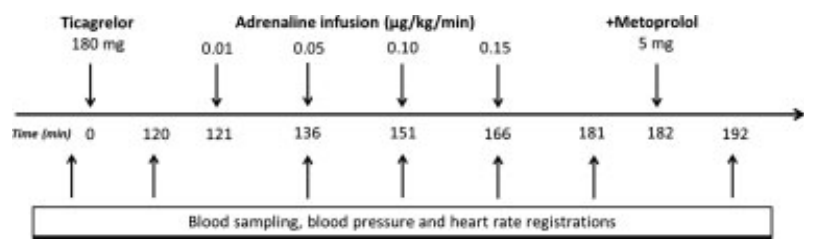

Fig. 1 Flow chart of the treatment during the investigational visit. hours after ticagrelor administration, new registrations and blood sampling were conducted. Adrenaline (Adrenalin 1mg/ $\mathrm{mL}$; Mylan, Canonsburg, Pennsylvania, United States) diluted in glucose (Glucose Baxter Viaflo $50 \mathrm{~g} / \mathrm{L}$; Baxter International Inc., Deerfield, Illinois, United States) to a concentration of 0.05 $\mathrm{mg} / \mathrm{mL}$ was prepared and given at a weight-adjusted rate of $0.01 \mu \mathrm{g} / \mathrm{kg} / \mathrm{min}$. The adrenaline infusion rate was gradually increased from 0.01 to $0.05,0.10$ and then to $0.15 \mu \mathrm{g} / \mathrm{kg} / \mathrm{min}$. After 15 minutes of each infusion, registrations and blood sampling were conducted according to - Fig. 1. At each timepoint, a maximum time deviation of 3 minutes was accepted. The last adrenaline infusion rate $(0.15 \mu \mathrm{g} / \mathrm{kg} / \mathrm{min})$ was maintained after the registrations and blood sampling had been performed and given in combination with an intravenous injection of $5 \mathrm{mg}$ metoprolol (Metoprolol $1 \mathrm{mg} / \mathrm{mL}$; Abcur, Helsingborg, Sweden) and registrations and blood sampling were then repeated after 10 minutes (-Fig. 1). The study procedure lasted for approximately 4 hours and the study participant was kept under observation for an additional 4 hours. Blood pressure and heart rate registrations were conducted at all seven time-points as well as every 30 minutes post last blood sampling during the following 4 hours of observation.

The study protocol stipulated that the adrenaline infusion should be stopped if the systolic blood pressure exceeded $180 \mathrm{~mm} \mathrm{Hg}$ or the heart rate exceeded 120 beats/min.

Phone follow-up calls were conducted to each participant $24 \pm 4$ and $72 \pm 4$ hours after ticagrelor administration. During the calls, the study participants were asked about their well-being and if they had had any adverse events since the investigational visit.

\section{Analyses}

At each time-point for blood sampling (-Fig. 1), one EDTA tube (Greiner Bio-One, International $\mathrm{GmbH}$, Kremsmünster, Austria) was collected for analysis of adrenaline plasma concentration. The blood tube was placed on ice directly after sampling and was centrifuged for 10 minutes at 2,000 g and $4^{\circ} \mathrm{C}$ within 30 minutes of collection. The plasma was stored in cryotubes (Sarstedt, Nümbrecht, Germany) at $-70^{\circ}$ $\mathrm{C}$ for subsequent analysis with high-performance liquid chromatography. In addition, two hirudin tubes were collected $(0.15 \mathrm{mg} / \mathrm{L}$, Roche Diagnostics $\mathrm{GmbH}$, Mannheim, Germany) for platelet aggregation and activation analysis and one citrated tube $(0.109 \mathrm{M}$ citrate, BD, Franklin Lakes, New Jersey, United States) for clot formation analysis.

\section{Impedance Aggregometry}

Whole blood impedance aggregometry (Multiplate; Roche Diagnostics, Basel, Switzerland) was used to evaluate platelet aggregation as previously described. ${ }^{19}$ This method has an intra-assay variability of $6 \pm 3 \%$ (mean coefficient of variation \pm standard deviation) while the maximum intra-individual variability was $18 \%$ when measured over a period of 4 months. ${ }^{19}$ Briefly, platelet aggregation is induced by agonists and the impedance between two sets of electrodes in a test cell is measured. The impedance increases as platelets aggregate on the electrodes and the results are presented 
as aggregation curves. The area under the curve (mean value of the two aggregation curves) was used to quantify platelet aggregation and is reported in aggregation units (U). The tests used in the present study were ADP-HS test (final concentration: $6.3 \mu \mathrm{M}$ ADP and $9.4 \mathrm{nM}$ prostaglandin E1), which evaluates $\mathrm{P}_{2} \mathrm{Y}_{12}$-receptor-dependent aggregation, ASPI test (final concentration: $0.5 \mathrm{mM} \mathrm{AA}$ ), which assesses cyclooxygenase-dependent thromboxane formation and its subsequent aggregation, and TRAP test (final concentration: $32 \mu \mathrm{M}$ TRAP), which evaluates PAR-1-receptor-dependent aggregation.

\section{Flow Cytometry}

To evaluate platelet activation, flow cytometry was used to measure the binding of PAC-1 (binds to the activated fibrinogen receptor glycoprotein IIb/IIIa $)^{20}$ and expression of the platelet activation marker P-selectin (CD62P). Duplicate samples were prepared containing either no agonists (unstimulated), ADP $(6.5 \mu \mathrm{M})$ or TRAP ( $32 \mu \mathrm{M}$, positive control). To keep the volume constant, $\mathrm{NaCl}$ (9 mg/mL; Fresenius Kabi, Bad Homburg, Germany) was added to unstimulated samples. Antibodies binding to the platelet activation markers were added to the tubes: anti-GPIb-PE (final concentration: $2.5 \mu \mathrm{g} / \mathrm{mL}$; CD42b, platelet surface marker; Dako, Agilent Technologies, Santa Clara, California, United States), PAC-1-FITC (final concentration: $0.56 \mu \mathrm{g} /$ $\mathrm{mL}$; BD Biosciences, San José, California, United States) and anti-P-selectin-APC (final concentration: $0.17 \mu \mathrm{g} / \mathrm{mL}$; BD Biosciences). For dilution and avoidance of non-specific binding of antibodies, HEPES-buffer (137 mM NaCl, $2.7 \mathrm{mM} \mathrm{KCl,} 1 \mathrm{mM}$ $\mathrm{MgCl}_{2}$, 5.6 mM glucose, $20 \mathrm{mM}$ Hepes and 0.1\% BSA, pH 7.40) was added. ${ }^{20}$ Background control samples were prepared for the first, second and sixth blood sampling time-points. The background controls consisted of IgG-APC (final concentration: $0.17 \mu \mathrm{g} / \mathrm{mL}$; BD Biosciences) as control for anti-P-selectin-APC to set the boundary between positively and negatively stained platelets. To set the PAC-1-FITC gate, the background control sample was diluted in HEPES-buffer with $10 \mathrm{mmol} / \mathrm{L}$ ethylenediaminetetraacetic acid (EDTA) as this prevents all binding of PAC-1 to the fibrinogen receptor (GPIIb/IIIa). Gates were set to approximately acquire $1.5 \%$ positive platelets in the background control samples. ${ }^{21}$ Blood $(3 \mu \mathrm{L})$ was added at 10 -second intervals between the tubes resulting in a final volume of $36 \mu \mathrm{L}$. The reaction was stopped after 10 minutes of incubation at room temperature by the addition of $700 \mu \mathrm{L}$ HEPES-buffer at 10 -second intervals. Flow cytometry (FACSCalibur flow cytometer; BD Biosciences) was performed within 30 minutes after blood collection and 10,000 GPIb-positive platelet events were acquired and analysed using CellQuest Pro software (BD Biosciences). The within-run imprecision for PAC-1 and Pselectin expression was $11.3 \pm 5.9 \%$ (mean coefficient of variation \pm standard deviation) and $6.8 \pm 2.0 \%$ respectively when unstimulated, $2.2 \pm 1.3$ and $6.5 \pm 4.0 \%$ respectively when induced by ADP and $1.1 \pm 0.6$ and $2.7 \pm 2.2 \%$ respectively when induced by TRAP.

\section{Rotational Thromboelastometry}

For analysis of clot formation, rotational thromboelastometry (ROTEM; Pentapharm GmbH, Munich, Germany) was used. Technical details have previously been described elsewhere. $^{22}$ The EXTEM test was used to assess the extrinsic pathway of coagulation by activation with tissue factor. The clotting time (CT), clot formation time (CFT) and maximum clot firmness (MCF) are reported.

\section{Statistics}

Data are presented in tables and boxplots with median and 25-75th percentiles. The different blood sampling time-points were compared in terms of blood pressure, heart rate, dyspnoea, adrenaline concentration, platelet aggregation, activation and clot formation using the nonparametric Friedman test for repeated measures. If a participant had missing data in a variable at some time-points, this test excludes the participant only at the specific timepoint and for that specific variable. A $p$-value of $<0.05$ was considered statistically significant. To determine which pairs of samples were significantly different, Wilcoxon signed-rank test (matched pairs) was used for post hoc analysis.

The sample size was based on preliminary results from our previous in vitro study. ${ }^{17}$ To achieve $80 \%$ power to detect a difference of $8.6 \mathrm{U}$ in ADP-induced aggregation with a twosided test at $\alpha=0.05$ and a standard deviation of $8.7 \mathrm{U}$, a sample of at least eight subjects was required. To control for attrition, a sample size of 10 was chosen. All statistical analyses were performed with SPSS version 22 (IBM Corporation, Armonk, New York, United States).

\section{Results}

\section{Participants}

Thirteen healthy volunteers were screened for eligibility and three were excluded due to meeting any exclusion criterion, yielding 10 eligible volunteers. There were missing data in all variables for one participant at sampling time-point $0.15 \mu \mathrm{g}$ / $\mathrm{kg} / \mathrm{min}$ with and without metoprolol due to hypertension during the treatment. Platelet activation was only assessed in the last eight participants due to technical issues with the flow cytometer.

\section{General}

One study participant suffered a mild vagal reaction with hypotension (systolic blood pressure: $80 \mathrm{~mm} \mathrm{Hg}$ ) when standing up from the bed 1 hour after the last blood sampling. Another participant became hypertensive during the treatment $(197 \mathrm{~mm} \mathrm{Hg}$ at $0.10 \mu \mathrm{g} / \mathrm{kg} / \mathrm{min}$ ). All participants were followed up by phone calls. No adverse events were reported during the phone follow-up calls.

\section{Haemodynamic Effects of Adrenaline and Metoprolol} Adrenaline infusion after ticagrelor administration increased systolic blood pressure and heart rate while the diastolic blood pressure and mean arterial pressure decreased (- Table 2). Metoprolol did not significantly influence blood pressure and heart rate 10 minutes after administration, compared with the same dose of adrenaline alone (-Table 2). 
Table 2 Haemodynamic effects and adrenaline plasma concentration. Results of blood pressure, heart rate, dyspnoea and adrenaline plasma concentration after ticagrelor administration and adrenaline infusion with and without metoprolol in healthy volunteers $(n=10)$. The laboratory's normal range for adrenaline plasma concentration is given in the left column. Values are median (25-75th percentiles)

\begin{tabular}{|l|l|l|l|l|l|l|l|}
\hline & Baseline & $\begin{array}{l}\text { After } \\
\text { ticagrelor } \\
(\mathbf{~ h})\end{array}$ & Adrenaline & Adrenaline & Adrenaline & Adrenaline & $\begin{array}{l}\text { Adrenaline }+ \\
\text { metoprolol } \\
(5 \mathrm{mg})\end{array}$ \\
\hline $\begin{array}{l}\text { Adrenaline infusion rate } \\
(\mu \mathrm{g} / \mathrm{kg} / \mathrm{min})\end{array}$ & & & 0.01 & 0.05 & 0.10 & 0.15 & 0.15 \\
\hline $\begin{array}{l}\text { Systolic blood } \\
\text { pressure }(\mathrm{mmHg})\end{array}$ & $\begin{array}{l}131 \\
(124-142)\end{array}$ & $\begin{array}{l}137 \\
(136-141)\end{array}$ & $\begin{array}{l}142 \\
(137-150)\end{array}$ & $\begin{array}{l}148 \\
(137-159)^{\mathrm{b}}\end{array}$ & $\begin{array}{l}160 \\
(147-175)^{\mathrm{a}}\end{array}$ & $\begin{array}{l}154 \\
(140-166)^{\mathrm{b}}\end{array}$ & $\begin{array}{l}152 \\
(136-157)^{\mathrm{b}}\end{array}$ \\
\hline $\begin{array}{l}\text { Diastolic blood } \\
\text { pressure (mmHg) }\end{array}$ & $66(53-72)^{\mathrm{b}}$ & $69(61-73)$ & $65(59-67)^{\mathrm{b}}$ & $59(51-61)^{\mathrm{a}}$ & $57(50-63)^{\mathrm{a}}$ & $54(48-57)^{\mathrm{b}}$ & $60(52-60)^{\mathrm{a}}$ \\
\hline $\begin{array}{l}\text { Mean arterial } \\
\text { pressure }(\mathrm{mmHg})\end{array}$ & $85(71-92)$ & $89(81-93)$ & $88(79-90)$ & $82(74-85)^{\mathrm{a}}$ & $81(73-85)^{\mathrm{b}}$ & $76(70-83)^{\mathrm{b}}$ & $80(73-84)^{\mathrm{b}}$ \\
\hline Heart rate (beats/min) & $66(62-67)$ & $61(54-68)$ & $72(63-74)^{\mathrm{a}}$ & $77(71-82)^{\mathrm{a}}$ & $82(74-86)^{\mathrm{a}}$ & $86(72-87)^{\mathrm{b}}$ & $78(75-80)^{\mathrm{b}}$ \\
\hline $\begin{array}{l}\text { Dyspnoea } \\
(\text { Borg scale 1-10) }\end{array}$ & $0(0-0.5)$ & $0(0-0)$ & $0(0-0)$ & $0(0-0.5)$ & $0.25(0-1)^{\mathrm{b}}$ & $0.5(0-1)^{\mathrm{b}}$ & $0(0-0)$ \\
\hline $\begin{array}{l}\text { Adrenaline plasma } \\
\text { concentration } \\
(0.16-0.55 \mathrm{nM})\end{array}$ & $\begin{array}{l}0.20 \\
(0.16-0.30)\end{array}$ & $\begin{array}{l}0.25 \\
(0.20-0.40)\end{array}$ & $\begin{array}{l}1.23 \\
(0.90-1.62)^{\mathrm{a}}\end{array}$ & $\begin{array}{l}5.70 \\
(5.41-6.49)^{\mathrm{a}}\end{array}$ & $\begin{array}{l}9.95 \\
(8.99-10.66)^{\mathrm{a}}\end{array}$ & $\begin{array}{l}14.28 \\
(14.13-16.82)^{\mathrm{a}}\end{array}$ & $\begin{array}{l}16.19 \\
(15.50-20.00)^{\mathrm{a}}\end{array}$ \\
\hline
\end{tabular}

${ }^{a} p<0.01$ vs. after ticagrelor ( $\left.2 \mathrm{~h}\right)$.

${ }^{\mathrm{b}} \mathrm{p}<0.05$ vs. after ticagrelor $(2 \mathrm{~h})$.

\section{Adrenaline Plasma Concentration}

Adrenaline infusion increased the plasma concentration of adrenaline significantly at all doses after ticagrelor administration (-Table 2). Metoprolol did not significantly influence the adrenaline concentration 10 minutes after administration, compared with the same dose of adrenaline alone (-Table 2 ).

\section{Platelet Activation}

Ticagrelor administration or adrenaline infusion did not significantly influence the unstimulated expression of active fibrinogen receptor (PAC-1 binding; Friedman test $p=0.24$; - Table 3). In contrast, ticagrelor administration decreased both ADP-induced and TRAP-induced PAC-1 binding compared

Table 3 Effects on platelet aggregation, activation and clot formation. Results of platelet aggregation $(n=10)$, activation $(n=8)$ and clot formation analysis $(n=10)$ after administration of ticagrelor and adrenaline infusion with and without metoprolol in healthy volunteers. Values are median (25-75th percentiles)

\begin{tabular}{|l|l|l|l|l|l|l|l|}
\hline & Baseline & $\begin{array}{l}\text { After } \\
\text { ticagrelor }(2 \mathrm{~h})\end{array}$ & Adrenaline & Adrenaline & Adrenaline & Adrenaline & $\begin{array}{l}\text { Adrenaline }+ \\
\text { metoprolol (5 mg) }\end{array}$ \\
\hline $\begin{array}{l}\text { Adrenaline infusion } \\
\text { rate }(\mu \mathrm{g} / \mathrm{kg} / \mathrm{min})\end{array}$ & & & 0.01 & 0.05 & 0.10 & 0.15 & 0.15 \\
\hline ADP $(\mathrm{U})$ & $59(54-68)^{\mathrm{a}}$ & $17(14-31)$ & $20(17-37)$ & $25(22-34)^{\mathrm{a}}$ & $25(21-34)^{\mathrm{b}}$ & $22(21-27)^{\mathrm{b}}$ & $25(22-28)^{\mathrm{b}}$ \\
\hline AA (U) & $79(77-83)^{\mathrm{a}}$ & $55(32-60)$ & $55(45-75)$ & $72(55-97)^{\mathrm{a}}$ & $79(68-92)^{\mathrm{a}}$ & $82(72-92)^{\mathrm{a}}$ & $89(77-92)^{\mathrm{a}, \mathrm{c}}$ \\
\hline TRAP $(\mathrm{U})$ & $106(95-118)^{\mathrm{a}}$ & $86(76-94)$ & $87(74-94)$ & $98(92-114)^{\mathrm{a}}$ & $107(101-124)^{\mathrm{a}}$ & $108(100-112)^{\mathrm{a}}$ & $113(107-118)^{\mathrm{b}}$ \\
\hline PAC-1 binding (\%) \\
\hline Unstimulated & $1.9(1.5-2.3)$ & $1.5(1.3-1.9)$ & $1.7(1.3-2.2)$ & $2.0(1.5-2.4)$ & $2.2(1.6-3.0)$ & $1.8(1.5-2.2)$ & $1.5(1.4-1.9)$ \\
\hline ADP-induced & $92(91-94)^{\mathrm{b}}$ & $29(22-35)$ & $33(26-42)^{\mathrm{b}}$ & $42(32-53)^{\mathrm{b}}$ & $46(38-57)^{\mathrm{b}}$ & $41(39-59)^{\mathrm{b}}$ & $37(34-58)^{\mathrm{b}, \mathrm{c}}$ \\
\hline TRAP-induced & $95(94-96)^{\mathrm{b}}$ & $64(50-69)$ & $68(58-70)^{\mathrm{b}}$ & $71(64-76)^{\mathrm{b}}$ & $73(69-79)^{\mathrm{b}}$ & $72(68-79)^{\mathrm{b}}$ & $72(70-78)^{\mathrm{b}}$ \\
\hline P-selectin (\%) & \multicolumn{7}{|l|l|l|l|l|}{} \\
\hline Unstimulated & $2.5(2.1-2.8)$ & $2.3(1.8-3.0)$ & $2.8(2.2-3.5)$ & $2.8(2.1-3.9)$ & $3.0(2.3-3.9)$ & $2.8(2.5-3.3)$ & $3.3(2.4-3.4)$ \\
\hline ADP-induced & $14.6(7.7-21.4)^{\mathrm{b}}$ & $3.7(3.0-4.3)$ & $4.5(3.6-6.0)^{\mathrm{b}}$ & $6.3(3.5-7.3)^{\mathrm{b}}$ & $7.7(4.7-8.6)^{\mathrm{b}}$ & $6.3(4.1-9.2)$ & $6.0(4.5-7.9)^{\mathrm{b}}$ \\
\hline TRAP-induced & $74(53-82)^{\mathrm{b}}$ & $57(36-72)$ & $60(44-73)$ & $64(49-76)^{\mathrm{b}}$ & $67(55-80)^{\mathrm{b}}$ & $68(56-82)^{\mathrm{b}}$ & $68(54-82)^{\mathrm{b}}$ \\
\hline EXTEM CT (s) & $78(71-85)$ & $77(75-80)$ & $80(76-91)$ & $78(73-82)$ & $76(69-83)$ & $75(72-78)$ & $73(70-78)$ \\
\hline EXTEM CFT (s) & $101(94-110)$ & $97(89-110)$ & $98(89-101)$ & $92(82-99)^{\mathrm{a}}$ & $88(70-91)^{\mathrm{a}}$ & $83(76-90)^{\mathrm{a}}$ & $77(73-86)^{\mathrm{a}}$ \\
\hline EXTEM MCF (mm) & $57(56-58)$ & $59(57-60)$ & $58(57-60)$ & $61(58-63)^{\mathrm{b}}$ & $62(60-64)^{\mathrm{b}}$ & $62(61-64)^{\mathrm{a}}$ & $62(62-63)^{\mathrm{a}}$ \\
\hline
\end{tabular}

Abbreviations: AA, arachidonic acid; ADP, adenosine diphosphate; CFT, clot formation time; CT, clotting time; MCF, maximum clot firmness; TRAP, thrombin receptor-activating peptide-6.

${ }^{a} p<0.01$ vs. after ticagrelor ( $2 \mathrm{~h}$ ).

${ }^{\mathrm{b}} \mathrm{p}<0.05$ vs. after ticagrelor $(2 \mathrm{~h})$.

${ }^{c} p<0.05$ vs. adrenaline alone $(0.15 \mu \mathrm{g} / \mathrm{kg} / \mathrm{min})$. 
with baseline ( $p=0.012$ for both). Adrenaline infusion increased both ADP-induced and TRAP-induced PAC-1 binding after ticagrelor administration, from median 29(22-35) to 46 $(38-57 \%)(p=0.012)$ for ADP and from $64(50-69)$ to 73 $(69-79 \%)(p=0.017)$ for TRAP at $0.10 \mu \mathrm{g} / \mathrm{kg} / \mathrm{min}$ for both. In the presence of ticagrelor, metoprolol reduced ADP-induced PAC- 1 binding compared with the same dose of adrenaline alone, from $41(39-59)$ to $37(34-58 \%)(p=0.028)$.

Ticagrelor administration or infusion of adrenaline did not significantly change unstimulated expression of P-selectin (Friedman test $p=0.22$; - Table 3). Both ADPinduced and TRAP-induced P-selectin expression decreased after ticagrelor administration compared with baseline ( $p=0.017$ and 0.012 , respectively). Adrenaline infusion increased both ADP-induced and TRAP-induced P-selectin expression after ticagrelor administration, from median 3.7 (3.0-4.3) to $7.7(4.7-8.6 \%)(p=0.012)$ at $0.10 \mu \mathrm{g} / \mathrm{kg} / \mathrm{min}$ for ADP and from $57(36-72)$ to $68(56-82 \%)(p=0.012)$ at $0.15 \mu \mathrm{g} / \mathrm{kg} / \mathrm{min}$ for TRAP. In the presence of ticagrelor, addition of metoprolol did not significantly influence Pselectin expression compared with the same dose of adrenaline alone $(p=0.24)$.

\section{Platelet Aggregation}

ADP-induced aggregation decreased after ticagrelor administration compared with baseline $(p=0.005$; - Fig. 2 and - Table 3). Adrenaline infusion increased ADP-induced aggregation after ticagrelor administration without evident doseresponse relationship, from median 17 (25-75th percentiles: $14-31)$ to $25(21-34)$ aggregation units $(p=0.012)$ at $0.10 \mu \mathrm{g} /$ $\mathrm{kg} / \mathrm{min}$. In the presence of ticagrelor, the addition of metoprolol did not significantly influence ADP-induced aggregation compared with the same dose of adrenaline alone $(p=0.18)$. Six of the seven study participants that had an ADP-induced aggregation lower than 22 units after ticagrelor administration showed increased levels above 22 units during adrenaline

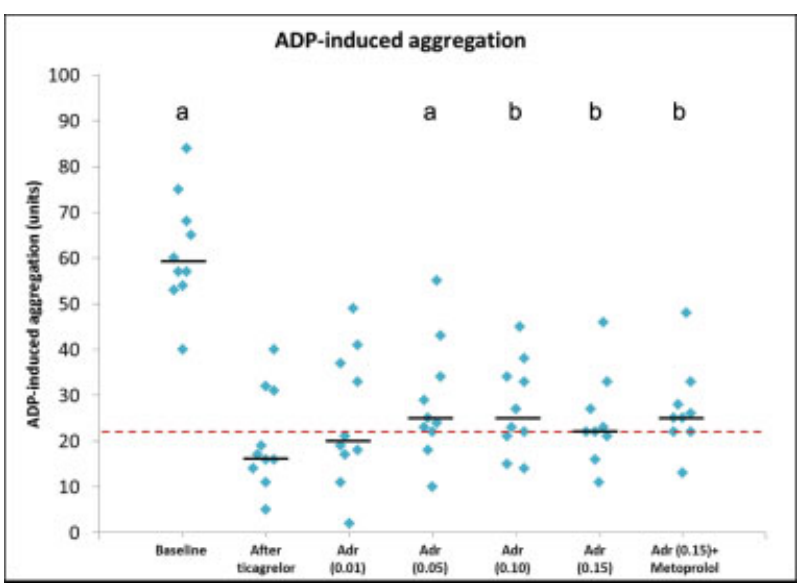

Fig. 2 Effect of ticagrelor, adrenaline (Adr) infusion (0.01, 0.05, 0.10 and $0.15 \mu \mathrm{g} / \mathrm{kg} / \mathrm{min}$ ) and metoprolol ( $5 \mathrm{mg}$ ) on ADP-induced aggregation in healthy volunteers $(n=10)$. The blue diamond shapes denote aggregation for each study participant while the black lines denote the median values. The dashed red line denotes the level of 22 units. Friedman test for repeated measures was used with Wilcoxon signed-rank test for post hoc analysis. ${ }^{\mathrm{a}} p<0.01,{ }^{\mathrm{b}} p<0.05$ vs. after ticagrelor. infusion (-Supplementary Fig. S1, available in the online version).

AA-induced aggregation decreased after ticagrelor administration compared with baseline ( $p=0.005$; - Table 3). Adrenaline infusion increased AA-induced aggregation after ticagrelor administration $(p=0.008$ for $0.15 \mu \mathrm{g} / \mathrm{kg} /$ $\mathrm{min})$. In the presence of ticagrelor, the combination of adrenaline and metoprolol increased AA-induced aggregation more than adrenaline alone $(p=0.011)$.

TRAP-induced aggregation decreased after ticagrelor administration compared with baseline ( $p=0.007$; - Table 3). Adrenaline increased TRAP-induced aggregation after ticagrelor administration ( $p=0.008$ for $0.15 \mu \mathrm{g} / \mathrm{kg} / \mathrm{min}$ ). In the presence of ticagrelor, the addition of metoprolol did not significantly influence TRAP-induced aggregation compared with adrenaline alone $(p=0.68)$.

\section{Clot Formation}

Ticagrelor administration did not significantly change CT, CFT and MCF (- Table 3). Adrenaline infusion after ticagrelor administration did not significantly alter CT while it shortened CFT and increased MCF. In the presence of ticagrelor, metoprolol did not have any significant influence on CFT or MCF compared with the same dose of adrenaline alone.

\section{Discussion}

The main finding of the present study was that infusion of clinically relevant doses of adrenaline to ticagrelor-treated subjects enhanced agonist-induced platelet activation and aggregation, and clot formation. However, the effect was limited and did not normalize platelet function.

On-going or recently discontinued treatment with a $\mathrm{P}_{2} \mathrm{Y}_{12}$-receptor antagonist such as ticagrelor increases the risk of major perioperative bleeding during cardiac surgery. $^{2,7}$ The bleeding risk in patients on $\mathrm{P}_{2} \mathrm{Y}_{12}$-receptor antagonists correlates to the residual ADP-dependent platelet aggregability ${ }^{7-9}$ and a cut-off value of $22 \mathrm{U}$ with impedance aggregometry has in two independent studies been suggested for when cardiac surgery can be performed without an increased bleeding risk. ${ }^{7,8}$ In the present study, adrenaline enhanced median ADP-induced platelet aggregation from 17 units to 25 units. Seven participants had ADPinduced aggregation $<22$ units after ticagrelor administration, six of these reached $>22$ units during adrenaline infusion.

We have previously shown that adrenaline improves ADPinduced aggregation and activation also in blood samples from patients on DAPT with acetylsalicylic acid and ticagrelor. ${ }^{17}$ The present study extends this in vitro observation to healthy subjects treated with ticagrelor and clinically relevant doses of adrenaline. Markedly lower plasma concentrations of adrenaline were needed in the present study to significantly increase ADP-induced aggregation in vivo (6-14 nM) compared to those in our in vitro study (153 and $770 \mathrm{nM}$ ). Even higher concentrations of adrenaline $(1 \mu \mathrm{M})$ restored ADPinduced aggregation in the presence of ticagrelor in blood samples from healthy donors in another in vitro study. ${ }^{23}$ The 
reason for why so much higher adrenaline concentrations are needed in vitro to enhance platelet reactivity is unclear. No previous studies have assessed the effect of adrenaline infusion in ticagrelor-treated subjects. However, in healthy volunteers without platelet inhibition, an adrenaline infusion at $0.07 \mu \mathrm{g} /$ $\mathrm{kg} / \mathrm{min}$ and a resulting plasma concentration of $3.34 \mathrm{nM}$ improved platelet aggregation. ${ }^{24}$ In the present study, the ADP-induced aggregation after an in vivo adrenaline infusion increased to the same extent as in the in vitro study, i.e., approximately to $25 \mathrm{U}$. No obvious dose-dependent effect of adrenaline was observed in vivo; instead all doses from 0.05 to $0.15 \mu \mathrm{g} / \mathrm{kg} / \mathrm{min}$ increased ADP-induced aggregation to the same extent. This may be explained by desensitization of the $\alpha_{2 \mathrm{~A}}$-receptors on the platelets during the continuous infusion of adrenaline. In a previous study, the affinity for the $\alpha_{2 \mathrm{~A}}$-receptor was shown to decrease after 2 hours of infusion of adrenaline at $0.05 \mu \mathrm{gg} / \mathrm{kg} / \mathrm{min}^{25}$ In another study on untreated healthy volunteers, adrenaline's ability to reduce the level of cyclic adenosine monophosphate (cAMP) was diminished after 2 hours of infusion of adrenaline (gradually increased to $0.06 \mu \mathrm{g} / \mathrm{kg} / \mathrm{min}$ ). ${ }^{26}$ In that study, the aggregation in response to ADP in vitro did not significantly change after 2 hours of infusion. ${ }^{26}$ The lack of dose-dependency in the present study is in contrast to our in vitro study where the effect was concentration-dependent. ${ }^{17}$ In the present study, the concentration was increased step-wise in contrast to the in vitro study, which as stated above may lead to desensitization. Larger in vivo studies are thus necessary to determine whether an optimal dose of adrenaline for improvement of ADPinduced platelet aggregation can be determined.

No previous studies have evaluated platelet function during increasing infusion rates of adrenaline in subjects on $\mathrm{P}_{2} \mathrm{Y}_{12}$-receptor antagonist treatment. However, in two studies infusion of adrenaline $(0.07 \mu \mathrm{g} / \mathrm{kg} / \mathrm{min})$ enhanced platelet aggregation in healthy volunteers without platelet inhibition. ${ }^{24,27}$ In contrast, adrenaline infusion $(0.06 \mu \mathrm{g} / \mathrm{kg} /$ min) did not improve ADP-induced aggregation compared with saline only in another study in untreated healthy volunteers. ${ }^{28}$ The conflicting results between the previous studies may at least partially be due to the different methods used for platelet aggregation analysis. In the first two studies, ${ }^{24,27}$ filtragometry was used which detects the time it takes for platelet aggregates to occlude a filter, while in the other study, ${ }^{28}$ an aggregometer detecting changes in optical density in platelet-rich plasma was used.

The effect of adrenaline on ADP-induced platelet activation and aggregation in ticagrelor-treated subjects may possibly be explained by its action on signalling pathways in the platelets. ADP induces activation and aggregation via the G-proteincoupled receptors $\mathrm{P}_{2} \mathrm{Y}_{1}{ }^{29}$ and $\mathrm{P}_{2} \mathrm{Y}_{12}{ }^{30,31}$ Responses from both signalling pathways are needed for a normal ADP-induced activation and aggregation response. ${ }^{14,32-34}$ Ticagrelor binds to the P2 $\mathrm{Y}_{12}$-receptor and inhibits its activation by ADP. Adrenaline binds to the $\alpha_{2 \mathrm{~A}}$-receptor resulting in the activation of a pathway mimicking the $\mathrm{P}_{2} \mathrm{Y}_{12}$-mediated pathway. ${ }^{14-16}$ Thus, adrenaline may increase ADP-induced activation and aggregation in ticagrelor-treated subjects as responses from both pathways may be achieved. An alternative explanation is that the platelet concentration increases with infusion of adrenaline resulting in a better aggregation response. Adrenaline infusion has previously been shown to decrease the splenic platelet pool size and increase the venous platelet concentration. ${ }^{35}$ In the present study, we did not measure platelet concentration during the adrenaline infusion and can therefore not verify this. However, all participants had a platelet concentration within the normal range (ranged between 180-307 $\times 10^{9} / \mathrm{L}$ ) at the screening visit. Only a platelet concentration of $\leq 100 \times 10^{9} / \mathrm{L}$ has previously been shown to affect platelet aggregation measured with impedance aggregometry. ${ }^{36}$

Adrenergic agents such as adrenaline and noradrenaline are often used in cardiac surgery during and after cardiopulmonary bypass to increase blood pressure in hypotensive patients. Thus the use of adrenaline during cardiac surgery is already established, although not for the purpose of enhancing platelet reactivity. Adrenaline causes an increase in heart rate and systolic blood pressure ${ }^{37}$ and this may limit its use as a platelet-enhancing agent during and immediately after surgery in patients on DAPT. To counteract the effect of adrenaline on heart rate and systolic blood pressure, a $\beta$ blocker may be administered. However, it has not previously been investigated if this would also reduce the effect of adrenaline on platelet reactivity. This was tested in the present study by concomitant administration of metoprolol with the highest dose of adrenaline. The results suggest that administration of a $\beta_{1}$-selective blocker, such as metoprolol, does not negatively impact the effect of adrenaline on platelets (with the exception of lower ADP-induced PAC-1 binding). Hence, $\beta_{1}$-selective blockers may be used if tachycardia and hypertension occur during adrenaline infusion.

In the present study, infusion of adrenaline also improved clot formation. The antiplatelet effect of ticagrelor cannot be detected using viscoelastic coagulation tests alone, as evident by the absence of significant differences in coagulation parameters between baseline and measurements after ticagrelor administration (- Table 3). However, after ticagrelor administration, adrenaline infusion still shortened CFT and increased MCF. This improvement is most likely due to adrenaline's effect on platelets yielding a better platelet function and ultimately a better clot formation. Alternative explanations include increased platelet concentration as discussed above ${ }^{35}$ and effects on von Willebrand factor and factor VIII coagulant activity. ${ }^{38}$

The present study has important limitations. Only men were included to avoid effect of the hormone cycle on platelet function..$^{39}$ Also, adrenaline has many off-target effects which could limit its use. However, the use of adrenaline is already established in cardiac surgery patients. Furthermore, ticagrelor is mostly used together with acetylsalicylic acid as DAPT. We used only ticagrelor since we wanted to avoid a further increased bleeding risk for the participants as our primary objective was to study the effect of adrenaline on ADP-induced aggregation. This could limit the clinical relevance of the present study. However, an effect of adrenaline in patients treated with both acetylsalicylic acid and ticagrelor is plausible since adrenaline also improves in vitro platelet aggregation in the presence of acetylsalicylic acid. ${ }^{17,40}$ The sample size was 
small and therefore it cannot be excluded that the observed results were found by chance. Hence, this study is hypothesisgenerating rather than conclusive and the results need to be confirmed in larger studies on healthy volunteers and patients with coronary artery disease. In addition, we did not include a control group receiving placebo instead of adrenaline. Also, we did not measure platelet function and clot formation after the adrenaline infusion was completed. Moreover only one device was used to measure ADP-induced aggregation, we only used the ADP-HS test, and not the ADP test, and only a single concentration of each agonist was tested. Finally, platelet concentration was only analysed at the screening visit and not during the adrenaline infusion. It is not known if there is an association between platelet concentration and the antiplatelet effect of ticagrelor.

\section{Conclusion}

The results demonstrate that infusion of adrenaline at clinically relevant doses improves platelet reactivity and clot formation in ticagrelor-treated subjects. Adrenaline could thus potentially be used to prevent bleeding complications in ticagrelor-treated patients. Larger studies in patients on DAPT are necessary to confirm our findings and to evaluate if the effects are sufficient to improve perioperative haemostasis.

\section{What is known about this topic?}

- Ticagrelor inhibits ADP-induced platelet aggregation by binding to the platelet $\mathrm{P}_{2} \mathrm{Y}_{12}$-receptor. Platelet supplementation has limited effect on ADP-induced platelet aggregation in the presence of ticagrelor.

- Adrenaline binds to platelet $\alpha_{2 \mathrm{~A}}$-receptor which has the same downstream effects as the $\mathrm{P}_{2} \mathrm{Y}_{12}$-receptor.

- Adrenaline enhances in vitro ADP-induced platelet activation and aggregation in blood samples from patients with on-going ticagrelor treatment.

\section{What does this paper add?}

- In this paper, we report for the first time that adrenaline infusion at clinically relevant doses enhances ADPinduced platelet activation and aggregation, and clot formation in ticagrelor-treated healthy volunteers.

- Low-dose adrenaline infusion could potentially be used to prevent or reduce bleeding complications in ticagrelor-treated patients in need of acute surgery.

\section{Funding}

This work was supported by the Swedish Heart and Lung Foundation (grant number 20150587 to A.J.) and the Västra Götaland Region (grant number ALFGBG-725131 to A.J.). The study sponsors had no influence on study design, analysis and interpretation of data, writing the paper or in the decision to submit the paper for publication.
Conflict of Interest

None declared.

\section{Acknowledgments}

The authors thank Gothia Forum for providing excellent support throughout the study period. We also thank research staff Eva Berg, Maria Tellin and Caroline Ivarsson for their great assistance during the study.

\section{References}

1 Wallentin L, Becker RC, Budaj A, et al; PLATO Investigators. Ticagrelor versus clopidogrel in patients with acute coronary syndromes. N Engl J Med 2009;361(11):1045-1057

2 Hansson EC, Jidéus L, Åberg B, et al. Coronary artery bypass grafting-related bleeding complications in patients treated with ticagrelor or clopidogrel: a nationwide study. Eur Heart J 2016;37 (02):189-197

3 Hansson EC, Shams Hakimi C, Åström-Olsson K, et al. Effects of ex vivo platelet supplementation on platelet aggregability in blood samples from patients treated with acetylsalicylic acid, clopidogrel, or ticagrelor. Br J Anaesth 2014;112(03):570-575

4 O'Connor SA, Amour J, Mercadier A, et al; ACTION Study Group. Efficacy of ex vivo autologous and in vivo platelet transfusion in the reversal of P2Y12 inhibition by clopidogrel, prasugrel, and ticagrelor: the APTITUDE study. Circ Cardiovasc Interv 2015;8(11):e002786

5 Teng R, Carlson GF, Nylander S, Andersson TL. Effects of autologous platelet transfusion on platelet inhibition in ticagrelortreated and clopidogrel-treated subjects. J Thromb Haemost 2016;14(12):2342-2352

6 Valgimigli M, Bueno H, Byrne RA, et al; ESC Scientific Document Group; ESC Committee for Practice Guidelines (CPG); ESC National Cardiac Societies. 2017 ESC focused update on dual antiplatelet therapy in coronary artery disease developed in collaboration with EACTS: the task force for dual antiplatelet therapy in coronary artery disease of the European Society of Cardiology (ESC) and of the European Association for CardioThoracic Surgery (EACTS). Eur Heart J 2018;39(03):213-260

7 Malm CJ, Hansson EC, Åkesson J, et al. Preoperative platelet function predicts perioperative bleeding complications in ticagrelor-treated cardiac surgery patients: a prospective observational study. Br J Anaesth 2016;117(03):309-315

8 Ranucci M, Colella D, Baryshnikova E, Di Dedda U; Surgical and Clinical Outcome Research (SCORE) Group. Effect of preoperative P2Y12 and thrombin platelet receptor inhibition on bleeding after cardiac surgery. Br J Anaesth 2014;113(06):970-976

9 Mahla E, Prueller F, Farzi S, et al. Does platelet reactivity predict bleeding in patients needing urgent coronary artery bypass grafting during dual antiplatelet therapy? Ann Thorac Surg 2016;102(06):2010-2017

10 Spalding A, Vaitkevicius H, Dill S, MacKenzie S, Schmaier A, Lockette W. Mechanism of epinephrine-induced platelet aggregation. Hypertension 1998;31(02):603-607

11 Mills DC, Roberts GC. Effects of adrenaline on human blood platelets. J Physiol 1967;193(02):443-453

12 Lasch P, Jakobs KH. Agonistic and antagonistic effects of various alpha-adrenergic agonists in human platelets. Naunyn Schmiedebergs Arch Pharmacol 1979;306(02):119-125

13 Jakobs KH, Saur W, Schultz G. Characterization of alpha- and betaadrenergic receptors linked to human platelet adenylate cyclase. Naunyn Schmiedebergs Arch Pharmacol 1978;302(03):285-291

14 Jin J, Kunapuli SP. Coactivation of two different G protein-coupled receptors is essential for ADP-induced platelet aggregation. Proc Natl Acad Sci U S A 1998;95(14):8070-8074

15 Woulfe D, Jiang H, Mortensen R, Yang J, Brass LF. Activation of Rap1B by G(i) family members in platelets. J Biol Chem 2002;277 (26):23382-23390 
16 Daniel JL, Dangelmaier C, Jin J, Kim YB, Kunapuli SP. Role of intracellular signaling events in ADP-induced platelet aggregation. Thromb Haemost 1999;82(04):1322-1326

17 Singh S, Malm CJ, Ramström S, Hesse C, Jeppsson A. Adrenaline enhances in vitro platelet activation and aggregation in blood samples from ticagrelor-treated patients. Res Pract Thromb Haemost 2018;2(04):718-725

18 Wittfeldt A, Emanuelsson H, Brandrup-Wognsen G, et al. Ticagrelor enhances adenosine-induced coronary vasodilatory responses in humans. J Am Coll Cardiol 2013;61(07):723-727

19 Tóth O, Calatzis A, Penz S, Losonczy H, Siess W. Multiple electrode aggregometry: a new device to measure platelet aggregation in whole blood. Thromb Haemost 2006;96(06):781-788

20 Shattil SJ, Hoxie JA, Cunningham M, Brass LF. Changes in the platelet membrane glycoprotein IIb.IIla complex during platelet activation. J Biol Chem 1985;260(20):11107-11114

21 Schmitz G, Rothe G, Ruf A, et al. European Working Group on Clinical Cell Analysis: Consensus protocol for the flow cytometric characterisation of platelet function. Thromb Haemost 1998;79 (05):885-896

22 Lang T, Bauters A, Braun SL, et al. Multi-centre investigation on reference ranges for ROTEM thromboelastometry. Blood Coagul Fibrinolysis 2005;16(04):301-310

23 Scavone M, Femia EA, Caroppo V, Cattaneo M. Inhibition of the platelet P2Y12 receptor for adenosine diphosphate does not impair the capacity of platelet to synthesize thromboxane A2. Eur Heart J 2016;37(44):3347-3356

24 Wallén NH, Goodall AH, Li N, Hjemdahl P. Activation of haemostasis by exercise, mental stress and adrenaline: effects on platelet sensitivity to thrombin and thrombin generation. Clin Sci (Lond) 1999;97(01):27-35

25 Hollister AS, FitzGerald GA, Nadeau JH, Robertson D. Acute reduction in human platelet alpha 2-adrenoreceptor affinity for agonist by endogenous and exogenous catecholamines. J Clin Invest 1983;72(04):1498-1505

26 Jones CR, Giembcyz M, Hamilton CA, et al. Desensitization of platelet alpha 2-adrenoceptors after short term infusions of adrenoceptor agonist in man. Clin Sci (Lond) 1986;70(02):147-153

27 Larsson PT, Hjemdahl P, Olsson G, Egberg N, Hornstra G. Altered platelet function during mental stress and adrenaline infusion in humans: evidence for an increased aggregability in vivo as measured by filtragometry. Clin Sci (Lond) 1989;76(04):369-376
28 Kjeldsen SE, Weder AB, Egan B, Neubig R, Zweifler AJ, Julius S. Effect of circulating epinephrine on platelet function and hematocrit. Hypertension 1995;25(05):1096-1105

29 Jin J, Daniel JL, Kunapuli SP. Molecular basis for ADP-induced platelet activation. II. The P2Y1 receptor mediates ADP-induced intracellular calcium mobilization and shape change in platelets. J Biol Chem 1998;273(04):2030-2034

30 Hollopeter G, Jantzen HM, Vincent D, et al. Identification of the platelet ADP receptor targeted by antithrombotic drugs. Nature 2001;409(6817):202-207

31 Zhang FL, Luo L, Gustafson E, et al. ADP is the cognate ligand for the orphan G protein-coupled receptor SP1999. J Biol Chem 2001;276 (11):8608-8615

32 Savi P, Beauverger P, Labouret C, et al. Role of P2Y1 purinoceptor in ADP-induced platelet activation. FEBS Lett 1998;422(03):291-295

33 Foster CJ, Prosser DM, Agans JM, et al. Molecular identification and characterization of the platelet ADP receptor targeted by thienopyridine antithrombotic drugs. J Clin Invest 2001;107(12): 1591-1598

34 Nylander S, Mattsson C, Ramström S, Lindahl TL. The relative importance of the ADP receptors, P2Y12 and P2Y1, in thrombininduced platelet activation. Thromb Res 2003;111(1-2):65-73

35 Wadenvik H, Kutti J. The effect of an adrenaline infusion on the splenic blood flow and intrasplenic platelet kinetics. Br J Haematol 1987;67(02):187-192

36 Hanke AA, Roberg K, Monaca E, et al. Impact of platelet count on results obtained from multiple electrode platelet aggregometry (Multiplate). Eur J Med Res 2010;15(05):214-219

37 Ensinger H, Lindner KH, Dirks B, Kilian J, Grünert A, Ahnefeld FW. Adrenaline: relationship between infusion rate, plasma concentration, metabolic and haemodynamic effects in volunteers. Eur J Anaesthesiol 1992;9(06):435-446

38 Jern C, Eriksson E, Tengborn L, Risberg B, Wadenvik H, Jern S. Changes of plasma coagulation and fibrinolysis in response to mental stress. Thromb Haemost 1989;62(02):767-771

39 Melamed N, Yogev Y, Bouganim T, Altman E, Calatzis A, Glezerman $M$. The effect of menstrual cycle on platelet aggregation in reproductive-age women. Platelets 2010;21(05):343-347

40 Grenegård M, Vretenbrant-Oberg K, Nylander M, et al. The ATPgated $\mathrm{P} 2 \times 1$ receptor plays a pivotal role in activation of aspirintreated platelets by thrombin and epinephrine. J Biol Chem 2008; 283(27):18493-18504 